\author{
Н. В. Зильберберг, доктор медицинских наук, профессор \\ ГБУ СО УрНИИДВиИ, Екатеринбург, Россия
}

Резюме. Дефицит жироподобных компонентов приводит к истончению гидролипидной пленки рогового слоя эпидермиса и повышению его проницаемости, развитию сухости кожи за счет увеличения трансэпидермальной потери влаги. У лиц с сухой и чувствительной кожей, склонной к раздражению, нарушение синтеза церамидов приводит не только к разрушению защитной липидной мантии, но и к снижению антимикробной защиты кожного покрова, изменению микробиоты кожи за счет колонизации условно-патогенными и патогенными бактериями. В статье обобщен клинический опыт комплексного применения новых косметических средств для ухода за сухой и чувствительной кожей лица, склонной к раздражению. Динамические клинические наблюдения, а также результаты оценки морфофункционального состояния кожи (увлажненность, питание, трансэпидермальная потеря влаги, рН-метрия, эластичность) доказывают целесообразность использования линейки специализированных косметических средств для восстановления защитной функции кожи и их благотворное влияние на видовой состав микробиома кожи лица.

Ключевые слова: наружные средства, сухая и чувствительная кожа, косметические средства.

Для цитирования: Зильберберг Н. В. Возможности восстановления морфофункционального состояния и микробиома кожи при комплексном космецевтическом уходе // Лечащий Врач. 2021; 5 (24): 32-36. DOI: 10.51793/OS.2021.62.20.007

\title{
Possibilities of restoring of the morphofunctional state and microbiome of the skin with complex cosmeceutical care
}

\section{N. V. Zilberberg}

Ural Scientific Research Institute of Dermatovenerology and Immunopathology, Ekaterinburg, Russia

Abstract. A deficiency of fat-like components leads to a thinning of the hydrolipidic film of the stratum corneum of the epidermis and an increase in its permeability, the development of dry skin due to an increase in transepidermal moisture loss. In persons with dry and sensitive skin prone to irritation, a violation of ceramide synthesis leads not only to the destruction of the protective lipid mantle, but also to a decrease in the antimicrobial protection of the skin, changes in the skin microbiota due to colonization by opportunistic and pathogenic bacteria. The article summarizes the clinical experience of the complex application of new cosmetics for the face for the care of dry and sensitive skin prone to irritation. Dynamic clinical observations, as well as the results of the assessment of the morphofunctional state of the skin (hydration, nutrition, transepidermal moisture loss, $\mathrm{pH}$-metric, elasticity), prove the feasibility of using a line of specialized cosmetics to restore the protective function of the skin and a beneficial effect on the species composition of the microbiome of the facial skin.

Keywords: external remedies, dry and sensitive skin.

For citation: Zilberberg N. V. Possibilities of restoring of the morphofunctional state and microbiome of the skin with complex cosmeceutical care // Lechaschy Vrach. 2021; 5 (24): 32-36. DOI: 10.51793/OS.2021.62.20.007

K ожный покров в эстетически значимых локализациях открытых участков кожи (лицо, особенно область век и вокруг губ) наиболее тонкий, менее эластичный и более проницаемый, что способствует легкому проникновению аллергенов и чужеродных микроорганизмов. Кожа лица подвержена наибольшему негативному воздействию внешних факторов, таких как низкая и высокая температура, солнечное излучение, детергенты, механическое раздражение и химически активные компоненты косметических средств. При этом кожа лица отличается значительными изменениями микроциркуляции с парадоксальной сосудистой

Контактная информация: zilberberg@mail.ru реакцией и повышенной неспецифической гиперреактивностью в ответ на воздействие триггерных раздражителей [1-4].

В настоящее время вызывает особый научный интерес изучение сочетания нарушений барьерной функции сухой и раздраженной кожи с колонизацией условно-патогенными и патогенными бактериями. Нарушение целостности кожного барьера объясняется дефектами генов структурных белков - филаггрина и лорикрина, участвующих в образовании рогового слоя эпидермиса, а также недостаточным синтезом липидов кожи (церамидов) и антимикробных пептидов [5-6]. Дефицит жироподобных компонентов приводит к истончению гидролипидной пленки рогового слоя эпидермиса и повышению его проницаемости, развитию сухости кожи за счет увеличения трансэпидермальной потери влаги. У лиц 
с сухой и чувствительной кожей, склонной к раздражению, нарушение синтеза церамидов приводит не только к разрушению защитной липидной мантии, но и к снижению антимикробной защиты кожного покрова, изменению микробиоты кожи за счет колонизации условно-патогенными и патогенными бактериями. Установлено, что патогенные бактерии, колонизирующие кожу, секретируют ферменты, которые еще больше усиливают трансэпидермальную потерю воды, замедляя при этом процессы восстановления барьерного слоя эпидермиса. Кроме того, особое значение в формировании дополнительных условий для инфицирования у лиц с сухой и чувствительной кожей, склонной к раздражению, придается снижению содержания антимикробных пептидов (кателицидинов и дефензинов) в коже [7-12].

Скорость бактериальной колонизации кожи напрямую зависит от выраженности сухости и раздражения кожи, площади ее поражения. Клеточные стенки $S$. aureus содержат рецепторы к ламинину и фибронектину эпидермиса и дермы, усиливающие адгезию стафилококка и позволяющие ему формировать бактериальную биопленку на поверхности кожи [8]. S. aureus способен вырабатывать не только адгезины, но и антифагоцитарные факторы и экзотоксины, при этом наиболее важную роль отводят энтеротоксинам А и В, вызывающим воспалительную реакцию в коже, сопровождающуюся активацией моноцитов и лимфоцитов, резким увеличением синтеза ряда провоспалительных цитокинов [13]. Одной из особенностей энтеротоксинов $S$. aureus является их способность проникать через эпидермальный барьер и действовать в качестве аллергенов, вызывая дегрануляцию тучных клеток и выработку базофилами гистамина [10, 14, 15].

С одной стороны, нарушение барьерных свойств кожного покрова создает предпосылки для присоединения вторичной инфекции, а с другой - изменение микробиома и обширная колонизация кожи $S$. aureus усугубляют нарушение структурной целостности кожного барьера, формируя порочный круг, приводящий к хронизации воспаления, сухости и гиперчувствительности кожи. Поэтому важным компонентом наружного ухода за сухой и раздраженной кожей лица является использование смягчающих и увлажняющих средств, способствующих восстановлению защитных свойств эпидермального барьера, обеспечивая при этом нормализацию качественного и количественного состава микробиома кожи. Пребиотическим эффектом обладают олигосахариды (соевый олигосахарид, фруктоолигосахариды), моносахариды (ксилит, раффиноза, сорбит, ксилобиоза и др.); дисахариды (лактулоза), полисахариды (целлюлоза, гемицеллюлоза, пектины, камеди, слизи, декстрин, инулин и др.), пептиды (соевые, молочные и др.), ферменты (протеазы сахаромицетов, $\beta$-галактозидазы микробного происхождения и др.), аминокислоты (валин, аргинин, глутаминовая кислота), антиоксиданты (витамины А, C, Е, каротиноиды, глутатион, $\mathrm{Q}_{10}$, соли селена и др.), ненасыщенные жирные кислоты (эйкозапентаеновая кислота и др.); растительные и микробные экстракты (лецитин, парааминобензойная кислота, лизоцим, лактоферрин, лектины, экстракты различных водорослей и др.) [7, 11, 16, 17].

Пребиотики, входящие в состав косметических средств, должны быть нетоксичными, не вызывать побочных эффектов при длительном применении, обладать стабильной клинической эффективностью, а также селективно стимулировать один вид или определенную группу микроорганизмов, резидентных для кожи.

Насущная потребность в расширении спектра дерматокосметических средств увлажняющего, питающего, противовоспалительного и антимикробного действия диктует необходимость поиска новых композиций и согласуется с прио- ритетным направлением импортозамещающих российских разработок инновационных продуктов.

В связи с изложенным выше целью нашего исследования явилась оценка эффективности и безопасности применения линейки косметических средств $P R O$-DERMASIL у лиц с чувствительной кожей, склонной к сухости и раздражению.

\section{Материалы и методы исследований}

Под динамическим наблюдением находились 27 женщин с чувствительной кожей, склонной к сухости и раздражению, в возрасте от 20 до 40 лет, использующих комплекс новых косметических средств линейки PRO-DERMASIL. Нанесение косметических средств на кожу лица осуществлялось последовательно в соответствии с инструкцией, в течение 28 дней. Были соблюдены критерии включения и исключения, подписаны информированные согласия на участие в исследовании.

Для оценки эффективности применения комплекса косметических средств анализировалась динамика клинических показателей состояния кожи лица (сухость, мелкопластинчатое шелушение и признаки раздражения).

Оценка упруго-эластичных свойств кожи лица осуществлялась с помощью щипковой пробы нижней трети щечной области (regio buccalis), которая расценивалась негативной, если кожа после взятия ее в складку не расправлялась в течение 3 секунд и более, позитивной - при восстановлении исходного состояния кожи в указанный интервал времени, а также на основании оценки динамики показателей кутометрии, основанных на оптической оценке степени всасывания и расслабления кожной складки при втяжении ее в отверстие датчика под действием отрицательного давления в диапазоне от 0 до 100\% (Courage and Khazaka Electronic, Германия).

Для объективизации оценки морфофункционального состояния кожи лица до, через 7, 14 и 28 дней применения косметических средств проводилась диагностика состояния кожи с использованием стандартизованных методик и оборудования (Courage and Khazaka Electronic, Германия):

- $\mathrm{pH}$-метрия кожи;

- оценка увлажненности эпидермиса кожи методом корнеометрии;

- оценка питающего действия на кожу методом себуметрии, основанным на фотометрическом определении пятен себума, оставшихся на специальной абсорбирующей пленке после ее контакта с кожей;

- оценка показателей мексаметрии кожи с измерением индекса эритемы (IE) на основании поглощения кожей света разной длины волны в красной, зеленой и инфракрасной областях спектра;

- оценка трансэпидермальной потери влаги (ТЭПВ) с поверхности кожи методом вапометрии за определенный временной промежуток, равный 15 секундам.

С целью изучения видового качественного и количественного состава факультативно-анаэробной и микроаэрофильной флоры микробиома кожи лица до, через 1, 14 и 28 дней применения комплекса косметических средств проводились микробиологические исследования. Количественный анализ, показывающий диагностическую значимость титров выросших колоний, выражали в $\lg \mathrm{KOE} /$ мл от среднего количества микроорганизмов. Идентификация выделенных культур микроорганизмов в соскобах кожи лица осуществлялась методом массспектрометрического профилирования бактерий на анализаторе VITEK MS (BioMerieux, Франция) по технологии MALDI-TOF (матричная лазерная время-пролетная масс-спектрометрия) с использованием Международной библиотеки референсных 
спектров рибосомальных белков различных видов микроорганизмов. Обработка данных осуществлялась при помощи программного обеспечения с указанием полного наименования микроорганизма до рода, вида и процента достоверности.

Статистический анализ данных проводился с использованием лицензионных программ StatPlus v5 и AnalystSoft Inc (США). Анализ полученных данных проводился с помощью непараметрических методов статистики. Результаты представлены в виде медианы $(\mathrm{Me})$ и межквартильного интервала (МКИ 25,0\%; 75,0\%). Для всех статистических критериев ошибка первого рода устанавливалась равной 0,05 . Нулевая гипотеза (отсутствие различий) отвергалась, если вероятность (р) не превышала ошибку первого рода.

\section{Характеристика косметических препаратов}

Линейка косметических препаратов для лица $P R O$-DERMASIL (Пенка-мусс для умывания $P R O$-DERMASIL для сухой и атопичной кожи, Крем для лица $P R O$-DERMASIL дневной для сухой и атопичной кожи и Крем для лица $P R O$-DERMASIL ночной для сухой и атопичной кожи) разработана для регулярного ухода за чувствительной кожей лица, склонной к сухости и раздражению. Препараты содержат в своем составе Комплекс, контролирующий микробиом, - Microbiome control complex (лизат лактобактерий, инулин, альфаглюкан олигосахарид, ферментированное масло оливы в различных сочетаниях, обусловленных технологической совместимостью с косметической основой), способствующий восстановлению гидролипидного барьера, приведению $\mathrm{pH}$ кожи к физиологической норме и нормализации микробиома кожи. Кроме того, в линейку PRO-DERMASIL входят Мицеллярная вода $P R O$-DERMASIL для сухой и атопичной кожи, Бальзам для губ $P R O$-DERMASIL для сухой и атопичной кожи и Крем для век PRO-DERMASIL для сухой и атопичной кожи. Косметические препараты не содержат спирта, отдушек, красителей и парабенов.

\section{Результаты и обсуждение}

При регулярном применении косметических средств линейки $P R O$-DERMASIL в течение 28 дней у 27 женщин с чувствительной кожей лица, склонной к сухости и раздражению, не было выявлено патологических кожных реакций в виде усиления сухости, гиперемии, шелушения, появления новых высыпаний и отека, а наличие отрицательных капельных и аппликационных проб показало отсутствие какого-либо раздражающего и сенсибилизирующего действия косметических средств.

У женщин с сухой, чувствительной и раздраженной кожей лица на фоне комплексного последовательного использова-

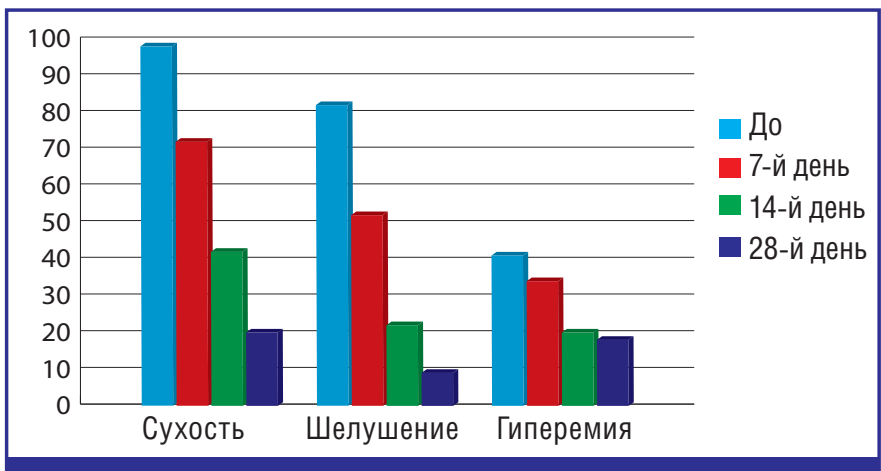

Рис. 1. Динамика клинических показателей состояния кожи лица при комплексном использовании косметических средств PRO-DERMASIL ния косметических средств Пенка-мусс для умывания $P R O$ DERMASIL для сухой и атопичной кожи, Крем для лица $P R O$ DERMASIL дневной для сухой и атопичной кожи и Крем для лица $P R O$-DERMASIL ночной для сухой и атопичной кожи оценивали клинические показатели состояния кожи (рис. 1).

Уже через 7 дней применения комплекса косметических средств удельный вес женщин с выраженной сухостью и шелушением кожи снизился на 25,9\% и 44,4\%, а через 14 дней применения - на 55,6\% и 69,6\% соответственно. Через 28 дней применения косметических препаратов удельный вес женщин с выраженной сухостью и шелушением кожи снизился на 77,8\% и 86,9\%. Положительная динамика наблюдалась и при анализе показателя гиперемии кожи лица. Так, через 14 дней применения косметических препаратов удельный вес лиц с признаками гиперемии кожи снизился на 50,0\%, а через 28 дней - на 58,3\%. Все участвовавшие в исследовании женщины отмечали удобство использования косметических средств при нанесении на кожу лица, а также их хорошие органолептические свойства.

Кроме оценки клинических показателей состояния кожи у женщин с чувствительной кожей лица, склонной к сухости и раздражению, проводилось мониторирование основных морфофункциональных показателей кожи при комплексном использовании косметических средств (PRO).

На начальном этапе исследования показатель увлажненности кожи (корнеометрия) в целом по группе составил 24,5 (МКИ 22,8; 28,9) у.е., что соответствовало значениям дегидратированной кожи. Через 7 дней регулярного применения косметических средств показатель корнеометрии увеличился до 32,5 (МКИ 30,0; 37,3) у.е., через 14 дней - до 39,0 (МКИ 35,0; 41,3) у.е., через 28 дней показатель составил 40,5 (МКИ 38,0; $43,3)$ у.е. (увеличение от исходного показателя на $65,3 \%$ ), что свидетельствовало о выраженном увлажняющем действии применяемых косметических средств.

Начальный показатель себуметрии в среднем по группе составил 2,0 (МКИ 1,0; 3,0) у.е., что соответствовало недостатку липидов в коже. Через 7 дней показатель себуметрии увеличился до 16,0 (МКИ 14,0; 26,5), через 14 дней составил 18,0 (МКИ 16,0; 27,0), а через 28 дней - 19,0 (МКИ 17,0; 29,5) у.е. (увеличение от исходного показателя в 9,5 раз), что свидетельствовало о хорошем питающем эффекте применения комплекса косметических средств.

Также отмечено положительное влияние косметических средств линейки $P R O-D E R M A S I L$ на состояние эпидермального барьера кожи лица. До начала исследования показатель вапометрии составил 10,5 (МКИ 8,0; 13,0) у.е., что было ниже оптимальных значений и соответствовало клинической картине сухой и шелушащейся кожи. Через 7 дней ежедневного регулярного применения косметических средств показатель трансэпидермальной потери влаги существенно улучшился, достиг оптимальных значений и составил 8,5 (МКИ 7,0; 11,0) у.е., через 14 дней показатель вапометрии составил 7,0 (МКИ $6,0 ; 9,0)$ у.е., что соответствовало оптимальным значениям и улучшению клинической картины. При длительном применении косметических средств в течение 28 дней показатель ТЭПВ сохранился на уровне достигнутых оптимальных значений: 6,0 (МКИ 5,0; 8,0) у.е., что свидетельствовало о стойком эффекте восстановления кожного барьера.

О выраженном противовоспалительном действии комплекса косметических средств $P R O$-DERMASIL свидетельствует улучшение показателя мексаметрии на очагах локального раздражения кожи лица. До применения косметических средств индекс эритемы (IЕ) составил 39,5 (МКИ 34,3; 48,0) у.е., что превышало оптимальные значения. Уже через 7 дней применения космети- 


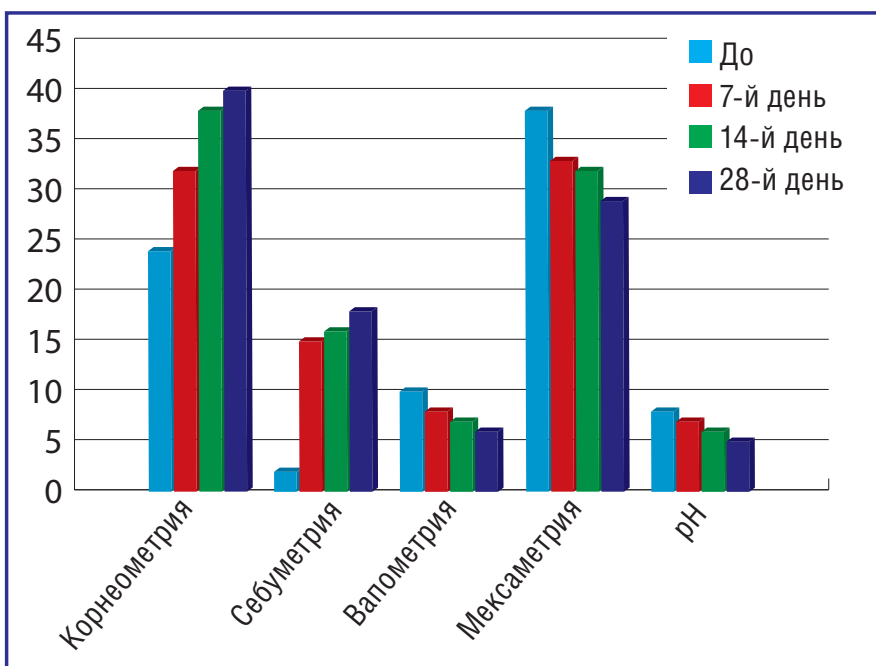

Рис. 2. Динамика показателей морфофункционального состояния кожи лица при комплексном применении косметических средств PRO-DERMASIL

ческих средств IЕ составил 34,5 (МКИ 32,0; 44,0) у.е. Через 14 дней применения косметических средств динамика IE значительная до 32,0 (МКИ 30,0; 41,8) у.е. (снижение от исходного показателя на 19,0\%). Через 28 дней применения косметических средств показатель мексаметрии достиг близких к оптимальным значений и составил 30,0 (МКИ 27,0; 37,0) у.е., что соответствовало клинической картине отсутствия раздражения и гиперемии кожи.

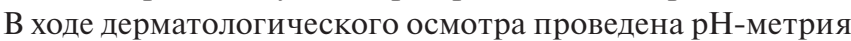
кожи лица. До применения исследуемых косметических средств $P R O$-DERMASIL значение $\mathrm{pH}$ кожи пробандов составляло 6,7 (МКИ 6,5; 6,9), через 7 дней показатель рН-метрии кожи лица составил 6,4 (МКИ 6,1; 6,6), через 14 дней - 5,9 (МКИ 5,8; 6,3), а через 28 дней достиг нормы для кожи - 5,5 (МКИ 5,4; 6,0).

Результаты исследования упруго-эластичных свойств кожи лица у женщин (кутометрия и щипковый тест) продемонстрировали, что регулярное локальное применение комплекса косметических средств линейки $P R O$-DERMASIL приводило к значительному улучшению состояния кожи лица (рис. 3).

При оценке показателя кутометрии начальные цифры соответствовали уровню удовлетворительных значений и составили 58,0\% (МКИ 54,0; 69,0). Через 28 дней регулярного применения комплекса косметических средств установлена тенденция улучшения упруго-эластичных свойств кожи лица: показатель кутометрии увеличился до границы оптимальных значений - 63,0\% (МКИ 56,0; 71,0; p > 0,05).

Положительная динамика наблюдалась и при анализе результатов щипкового теста кожи лица. После 7 дней регулярного применения комплекса косметических средств удельный вес женщин с негативным щипковым тестом составил 44,4\%, а по окончании исследования данный показатель составил $29,6 \%$ (снижение от исходного уровня на $38,5 \%$ ). Таким образом, несмотря на отсутствие существенного повышения показателя кутометрии, снижение удельного веса женщин с негативной щипковой пробой свидетельствует о благоприятном влиянии комплекса косметических средств на упруго-эластичные свойства кожи лица за счет увлажнения и улучшения питания кожи, а также восстановления функции эпидермального барьера.

Проведенное бактериологическое исследование видового состава микробиома кожи на фоне регулярного применения комплекса косметических средств $P R O$-DERMASIL показало достоверное снижение в 2,3 раза показателя микробной обсемененности кожи лица коагулазоположительными (S. aureus, $S$. intermedius, $S$. hyicus) и коагулазоотрицательными стафилококками ( $S$. epidermidis, $S$. haemolyticus, $S$. warneri, $S$. gallolyticus, S. capitis, $S$. hominis, $S$. saprophyticus, $S$. pseudintermedius, S. pasteuri), дрожжеподобными грибами рода Candida, а также бактериями рода Acinetobacter и Enterobacter. Так, в 76,9\% случаев микроорганизмы выявлялись в низком титре $10^{2}-10^{3}$ КОЕ/мл, а у $23,1 \%$ женщин через 28 дней применения комплекса косметических средств рост патогенных микроорганизмов при бактериологическом исследовании отсутствовал.

В целом установлено уменьшение спектра идентифицированных микроорганизмов с кожи лица: после 28 дней регулярного применения косметических средств микробный пейзаж включает в основном представителей резидентной и транзиторной нормобиоты кожи. Выявленное снижение внутривидового разнообразия обнаруживаемой микрофлоры кожи лица свидетельствует о благотворном влиянии комплекса косметических средств на микробиом кожи.

В линейку $P R O$-DERMASIL также входят Мицеллярная вода $P R O$-DERMASIL для сухой и атопичной кожи, Бальзам для губ $P R O$-DERMASIL для сухой и атопичной кожи и Крем для век $P R O$-DERMASIL для сухой и атопичной кожи.

Регулярное очищение кожи Мицеллярной водой $P R O$ DERMASIL для сухой и атопичной кожи в течение 28 дней способствует уменьшению сухости, локального мелкопластинчатого шелушения и гиперемии кожи лица - на 41,4\%, 45,5\% и $37,5 \%$ соответственно. Увлажняющее, успокаивающее, мягкое очищающее действие Мицеллярной воды PRO-DERMASIL для сухой и атопичной кожи позволяет улучшить увлажненность кожи на 11,8\%, а состояние эпидермального барьера - на 36,8\%.

Применение Бальзама для губ $P R O$-DERMASIL для сухой и атопичной кожи в течение 28 дней позволяет уменьшить сухость и гиперемию красной каймы губ и кожи вокруг рта и носа на $48,1 \%$ и $57,9 \%$ соответственно, уменьшить локальное мелкопластинчатое шелушение кожи на $45,5 \%$, наличие микротрещин - на 57,1\%, повысить увлажненность - на $36,1 \%$, уменьшить трансэпидермальную потерю влаги кожей периоральной зоны за счет активного увлажняющего и противовоспалительного эффектов, а также отсутствия раздражающего действия на кожу самого косметического средства - на 42,9\%.

При использовании Крема для век $P R O$-DERMASIL для сухой и атопичной кожи в течение 28 дней установлен клинический эффект уменьшения сухости кожи век на 53,6\%, мелкопластинчатого шелушения - на $60,9 \%$, отечности кожи - на $57,1 \%$,

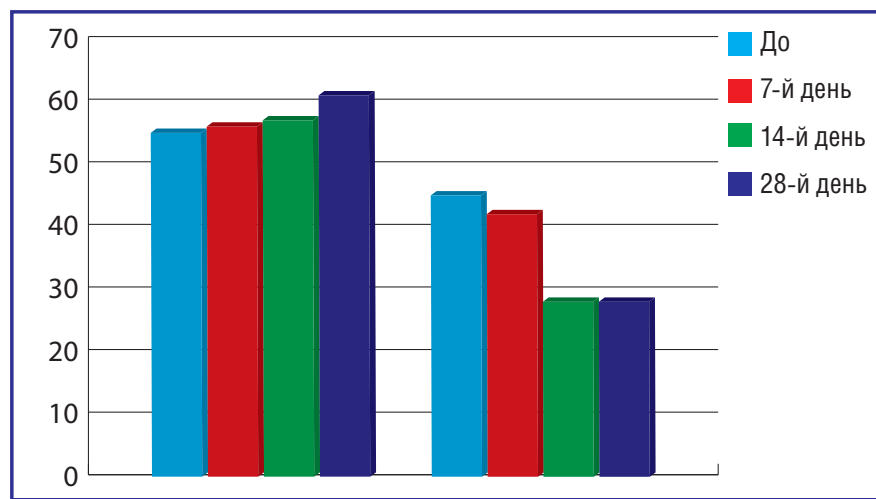

Рис. 3. Динамика показателей упруго-зластичных свойств кожи лица при комплексном использовании косметических средств PRO-DERMASIL 
а показатель увлажненности кожи улучшился на $30,8 \%$. Увлажняющее и противовоспалительное действие Крема для век PRO-DERMASIL для сухой и атопичной кожи позволяет улучшить показатель трансэпидермальной потери влаги до оптимальных значений. Значение индекса эритемы (IE) в очагах локального раздражения кожи век через 28 дней применения Крема для век $P R O$-DERMASIL для сухой и атопичной кожи снизилось на $17,6 \%$.

\section{Заключение}

Косметические препараты Пенка-мусс для умывания $P R O$ DERMASIL для сухой и атопичной кожи, Крем для лица $P R O$ DERMASIL дневной для сухой и атопичной кожи и Крем для лица PRO-DERMASIL ночной для сухой и атопичной кожи обладают гипоаллергенным составом, не оказывают раздражающего и сенсибилизирующего действия на кожу лица, не вызывают дискомфортных ощущений при длительном применении.

Высокая эффективность регулярного применения комплекса данных косметических препаратов в качестве средств базового ухода за чувствительной кожей лица, склонной к сухости и раздражению, подтверждена результатами динамического наблюдения и инструментальной диагностики состояния кожи. Доказано улучшение клинического и морфофункционального состояния кожи лица за счет восстанавливающего, увлажняющего, питающего, противовоспалительного и защитного действия комплекса косметических средств, а также их благотворного влияния на рН-баланс и на видовой состав микробиома кожи.

Комплексное применение косметических средств $P R O$ DERMASIL обеспечивает снижение показателя микробной обсемененности кожи лица в 2,3 раза с сохранением представителей резидентной и транзиторной нормобиоты. Выявленное снижение внутривидового разнообразия обнаруживаемой микрофлоры кожи лица в динамике применения комплекса косметических средств свидетельствует о благотворном влиянии на микробиом кожи.

Бережное очищение чувствительной, сухой, шелушашейся кожи лица Мицеллярной водой $P R O$-DERMASIL для сухой и атопичной кожи способствует сохранению ее гидролипидного барьера. При регулярном использовании Бальзама для губ PRO-DERMASIL для сухой и атопичной кожи установлено положительное влияние на состояние раздраженной, сухой, шелушащейся красной каймы губ за счет восстановления ее гидролипидного барьера и создания благоприятных условий для пролиферации клеток кожи периоральной зоны.

Регулярное применение Крема для век PRO-DERMASIL для сухой и атопичной кожи положительно влияет на состояние раздраженной, сухой, шелушащейся и отечной кожи век, восстанавливает ее гидролипидный барьер.

Полученные результаты позволяют констатировать целесообразность включения косметических препаратов линейки $P R O$-DERMASIL в клиническую практику дерматологов для формирования профессиональной программы ежедневного ухода за чувствительной кожей лица, склонной к сухости и раздражению.

КОНФЛИКТ ИНТЕРЕСОВ. Автор статьи подтвердил отсутствие конфрликта интересов, о котором необходимо сообщить.

CONFLICT OF INTERESTS. Not declared.

\section{Литература/References}

1. Maarouf M. et al. Head-and-neck dermatitis: Diagnostic difficulties and management pearls // Pediatric dermatology. 2018; 35 (6): 748-753.

2. Короткий Н. Г., Гамаюнов Б. Н. Причины сухости кожи и лечебно-косметический уход за ней // Клиническая дерматология и венерология. 2006; 4: 98-101.
[Korotkiy N. G., Gamayunov B. N. Prichiny sukhosti kozhi i lechebno-kosmeticheskiy ukhod za ney [Causes of dry skin and medical and cosmetic care for it] // Klinicheskaya dermatologiya i venerologiya. 2006; 4: 98-101.]

3. Чеботарев В. В., Чеботарева Н. В., Асхаков М. С., Бронникова Е. В. Чувствительная кожа: причины, методы терапии // Медицинский вестник Северного Кавказа. 2015; 3 (10): 319-322.

[Chebotarev V. V., Chebotareva N. V., Askhakov M. S., Bronnikova Ye. V. Chuvstvitel'naya kozha: prichiny, metody terapii [Sensitive skin: causes, methods of therapy] // Meditsinskiy vestnik Severnogo Kavkaza. 2015; 3 (10): 319-322.]

4. Кунгуров Н. В. Болезни кожи. Монография (атлас). Екатеринбург: УрНИИДВиИ, 2014. $176 \mathrm{c.}$

[Kungurov N. V. Bolezni kozhi. Monografiya (atlas). [Skin diseases. Monograph (atlas).] Yekaterinburg: UrNIIDViI, 2014. 176 P.]

5. Thyssen J. P., Kezic S. Causes of epidermal filaggrin reduction and their role in the pathogenesis of atopic dermatitis // J Allergy Clin Immunol. 2014; 134 (4): 792-799.

6. Visser M. J., Landeck L., Campbell L. E. et al. Impast of atopic dermatitis and lossof-function mutations in the filaggrin gene on the development of occupational irritant contact dermatitis // British Journal of Dermatology. 2013; 168: 326-332.

7. Савченко Е. С., Вердеренко В. В., Хайрутдинов В. Р., Стаценко А. В. Самцов A. B. Опыт применения наружного средства Glatte (кремпена 5\%-й мочевины) в терапии больных атопическим дерматитом // Эффективная фармакотерапия. 2015; 33: 4-8

[Savchenko Ye. S., Verderenko V. V., Khayrutdinov V. R., Statsenko A. V., Samtsov A. V. Opyt primeneniya naruzhnogo sredstva Glatte (krem-pena 5\%-y mocheviny) $\mathrm{v}$ terapii bol'nykh atopicheskim dermatitom [Experience of using the external agent Glatte (cream-foam of 5\% urea) in the treatment of patients with atopic dermatitis] // Effektivnaya farmakoterapiya. 2015; 33: 4-8.]

8. Стукова Е. И., Кениксфест Ю. В. Патогенетическое значение золотистого стафилококка при атопическом дерматите // Фундаментальные исследования. 2013; 7: 680-687.

[Stukova Ye. I., Keniksfest Yu. V. Patogeneticheskoye znacheniye zolotistogo stafilokokka pri atopicheskom dermatite [Pathogenetic significance of Staphylococcus aureus in atopic dermatitis] // Fundamental'nyye issledovaniya. 2013; 7: 680-687.]

9. Clausen M. L., Slotved H. C., Krogfelt K. A. et al. In vivo expression of antimicrobial peptides in atopic dermatitis // Experimental Dermatology. 2016; 125: 3-9.

10. Мурашкин Н. Н., Амбарчян Э. Т., Материкин А. И., Епишев Р. В. Роль нарушений эпидермального барьера при атопическом дерматите: современные концепции патогенеза заболевания // Вопросы современной педиатрии. 2018; 1: 85-88.

[Murashkin N. N., Ambarchyan E. T., Materikin A. I., Yepishev R. V. Rol' narusheniy epidermal'nogo bar'yera pri atopicheskom dermatite: sovremennyye kontseptsii patogeneza zabolevaniya [The role of epidermal barrier disorders in atopic dermatitis: modern concepts of the pathogenesis of the disease] // Voprosy sovremennoy pediatrii. 2018; 1: 85-88.]

11. Чернова И. Д., Морозова А. В., Восканян О. С. Косметический уход за кожей с приобретенным синдромом сухости // Тенденции развития науки и образования. 2019; 55: 40-44.

[Chernova I. D., Morozova A. V., Voskanyan O. S. Kosmeticheskiy ukhod za kozhey s priobretennym sindromom sukhosti [Cosmetic skin care with acquired dryness syndrome] // Tendentsii razvitiya nauki i obrazovaniya. 2019; 55: 40-44.]

12. Тамразова О. Б. Хрупкая кожа - фактор риска развития хронических дерматозов // Косметика и медицина. 2016; 3: 56-62.

[Tamrazova $O$. B. Khrupkaya kozha - faktor riska razvitiya khronicheskikh dermatozov [Fragile skin is a risk factor for the development of chronic dermatoses] // Kosmetika i meditsina. 2016; 3: 56-62.]

13. Pinchuk I. V., Beswick E. J., Reyes V. E. Staphylococcal enterotoxins // Toxins (Basel). 2010; 2 (8): 2177-2197.

14. Boguniewicz M., Leung D. Y. Recent insights into atopic dermatitis and implications for management of infectious complications // J Allergy Clin Immunol. 2010; 125 (1): 4-13.

15. Pastuszka M., Matych M., Kaszuba A. et al. Microorganisms in the etiopathogenesis of atopic dermatitis // Postep Derm Alergol. 2012; 29 (3): 215-221.

16. Пашинян А. Г., Джаваева Д. Г., Муликова Т. Ю. Эффективность лечебнокосметических средств по уходу за кожей у пациентов с хроническими дерматозами // Лечебное дело. 2014; 2: 13-16.

[Pashinyan A. G., Dzhavayeva D. G., Mulikova T. Yu. Effektivnost' lechebnokosmeticheskikh sredstv po ukhodu za kozhey u patsiyentov s khronicheskimi dermatozami [The effectiveness of medical and cosmetic products for skin care in patients with chronic dermatoses] // Lechebnoye delo. 2014; 2: 13-16.]

17. Адаскевич В. П. Клиническая эффективность эмолентов в базисной наружной терапии атопического дерматита // Дерматовенерология. Косметология. 2020; 1-2 (6): 128-134.

[Adaskevich V. P. Klinicheskaya effektivnost' emolentov v bazisnoy naruzhnoy terapii atopicheskogo dermatita [Clinical efficacy of emollients in the basic external therapy of atopic dermatitis] // Dermatovenerologiya. Kosmetologiya. 2020; 1-2 (6): 128-134.] 